\title{
Water status of cooked white salted noodles evaluated by MRI
}

\author{
Hsi-Mei Lai ${ }^{\text {a,* }}$, San-Chao Hwang ${ }^{\text {b }}$ \\ a Department of Agricultural Chemistry, National Taiwan University, No. 1, Sec. 4, Roosevelt Road, Taipei 10617, Taiwan \\ ${ }^{\mathrm{b}}$ Department of Electrical Engineering, National Taiwan University, Taipei, Taiwan
}

Received 31 March 2004; accepted 22 June 2004

\begin{abstract}
Transverse relaxation time $\left(T_{2}\right)$-weighted images and $T_{2}$ maps of white salted noodles (WSN) were investigated by magnetic resonance imaging technique. $T_{2}$-weighted images and $T_{2}$ maps clearly showed the differences in water status between noodles. The migration of moisture from surface regions to central regions of boiled WSN at different migration rates were investigated during storage. The distribution of $T_{2}$ values changed differently depending on the cooking and storage times. The small differences in $T_{2}$ values between surface region and central region of noodles cooked for 5 and 15 min were attributed to the limited water absorption during short cooking time, which resulted in high firmness. The changes in starch granules morphology observed under scanning electron microscope and the increase of noodle firmness measured by texture analyzer were significantly affected by the water status in noodles. The water status can be controlled by the cooking time.
\end{abstract}

(c) 2004 Elsevier Ltd. All rights reserved.

Keywords: Magnetic resonance imaging; White salted noodle; Water status; Transverse relaxation time; Firmness

\section{Introduction}

Noodles are the major wheat products in Asian diet and almost $40 \%$ of wheat is used for noodle production in Asian countries (Janto, Pipatsattayanuwong, Kruk, Hou, \& McDaniel, 1998). According to raw materials, processing, shape and the ways of retailing and eating, various types of noodles can be found in the markets. White salted noodle (WSN) is one of the most popular types of noodle in Taiwan, which is usually available as fresh (raw) or dried noodle. Recently, the refrigerated or frozen boiled noodles are gaining popularity because of the properties of convenience and readiness for serving. Since boiled WSN is a cooked, gelatinized starchybased food it is usually characterized by syneresis and

\footnotetext{
* Corresponding author. Tel.: +886-2-23630231x3061; fax: +886-223633123.

E-mail address: hmlai@ntu.edu.tw (H.-M. Lai).
}

increasing firmness during storage. The changes in the texture and taste of boiled WSN are usually one of the reasons to reject this product by consumers.

Eating quality is a relevant characteristic of noodles. Lots of studies have been performed correlating factors such as flour quality (Nagao et al., 1977; Oda, Yasuda, Okazaki, Yamauchi, \& Yokoyama, 1980; Seib, 2000; Wang \& Seib, 1996), formulation (Moss, Gore, \& Murray, 1987), and starch swelling properties (Crosbie, 1991; Kim \& Seib, 1993; Konik, Miskelly, \& Gras, 1992, 1993; Liang, 1999), to eating quality of noodles. Several workers have provided evidence that starch with high-swelling property is beneficial to the eating quality of WSN (Baik, Czuchajowska, \& Pomeranz, 1994; Crosbie, 1991; Konik et al., 1992; Seib, 2000; Wang \& Seib, 1996). Furthermore, the contributions of wheat starch to the eating quality of WSN is complicated by formulations, boiling conditions, and storage. Liang (1999) pointed out that after cooking and rinsing, Udon (one 
type of WSN) made with high-swelling starch gained water up to $75 \%$ moisture content, with moisture contents at $65 \%$ and $85 \%$ for the core and surface parts of the noodles, respectively. The roles of high-swelling starch in WSN included that quickly swollen starches fill pores near the noodle surface during the early stages of cooking, which result in the starch gel resisting erosion by cooking water and decrease cooking loss (Seib, 2000; Liang, 1999). However, the increased firmness of boiled noodles after storage significantly affected the eating quality of noodles and are always the most troublesome problem bothering manufacturers. It has been known that the increases of firmness of starchy-based food are mainly related to the retrogradation of starches. Although there are many factors affecting the degree of gelatinization and retrogradation rate of starch, the most important factors would be the status of water during processing and storage, such as moisture content, water mobility, water distribution and migration (Kojima, Horigane, Yoshida, Nagata, \& Nagasawa, 2001; Lai, Schmidt, Chiou, Slowinski, \& Day, 1993; Slade \& Levine, 1991).

Magnetic resonance imaging (MRI) technique was first developed as a non-destructive method for use in medical research and diagnosis, and the applications of the MRI technique in the field of food science has increased since the last decade (Schmidt \& Lai, 1991; Schmidt, Sun, \& Litchfield, 1996; Webb, Belton, Gil, \& Delgadillo, 2001). The major advantages of MRI are: (1) it is non-destructive and non-invasive; (2) it can provide spatial resolution; (3) it can provide diverse information such as proton density, water mobility, internal structure, chemical diffusion, temperature, and flow. MRI is pretty well regarded as a powerful tool for characterizing water mobility and distribution of foods during processing and storage (Fukuoka, Mihori, \& Watanabe, 2000; Kojima et al., 2001; Ruan \& Chen, 1998; Stapley, Hyde, Gladden, \& Fryer, 1997; Takano, Ishida, Koizumi, \& Kano, 2002; Takeuchi, Fukuoka, Gomi, Maeda, \& Watanabe, 1997). Although, the texture of boiled WSN evaluated by many objective measurements, such as a texture analyzer equipped with several of probes, has been reported in many works (Guan \& Seib, 1994; Oh, Seib, Deyoe, \& Ward, 1983; Yun, Rema, \& Quail, 1997), little information is available on the relationship of water status and texture changes of cooked WSN during storage. Therefore, the objective of this study was to non-invasively investigate the water status of cooked WSN, which were cooked with different time periods then stored up to $7.5 \mathrm{~h}$ at $18 \pm 2{ }^{\circ} \mathrm{C}$, by using a MRI technique. The firmness of cooked WSN measured by using a texture analyzer and the microstructure of noodles investigated by scanning electron microscope (SEM) were simultaneously carried out and the results were compared with the observations from MRI.

\section{Experimental}

\subsection{Materials}

The flour used for WSN making was purchased from a local flourmill (Taichung, Taiwan). The flour contained $8.43 \%$ of protein and $0.40 \%$ of ash on a dry basis determined according to the AACC methods (AACC, 1995). The wet gluten and dry gluten of flour determined by the method of AACC 38-10 (AACC, 1995) were $21.02 \%$ and $7.29 \%$, respectively.

\subsection{Preparation of white salted noodle}

The WSN was made from $500 \mathrm{~g}$ flour by adding $20 \mathrm{~g} \mathrm{~kg}^{-1}$ (on flour basis) $\mathrm{NaCl}$ solution at water absorption of $400 \mathrm{~g} \mathrm{~kg}^{-1}$ (on flour basis). Dough was mixed at low speed for $5 \mathrm{~min}$ in a KitchenAid desktop mixer (model KSMC50, KitchenAid, MI, USA). The crumbly dough was pressed into a cohesive rectangular block $(15 \times 35 \times 6 \mathrm{~cm}, W \times L \times H)$, and aged for $30 \mathrm{~min}$. The aged dough was passed through a laboratory noodle-making machine (SK-207, New Chung Hou Co., Ltd., Taipei, Taiwan) with an initial gap of $4.14 \mathrm{~mm}$. The dough sheet was folded and sheeted at a $4.14 \mathrm{~mm}$ gap for a total of six times. The sheet was packed in a PE plastic bag and aged for another $30 \mathrm{~min}$. The sheet was then progressively reduced by sheeting at a gap of 4.14, 3.53, 3.00 and $2.50 \mathrm{~mm}$. Rough edges were removed twice in between sheeting. The dough sheet was finally cut by a noodle cutter with $9 \mathrm{~mm}$ in width after it was aged for another $15 \mathrm{~min}$. Raw noodles ( $50 \mathrm{~mm}$ long) were cooked with boiling distilled water $(1: 20, \mathrm{w} / \mathrm{w})$ maintained at a rolling boil for five different cooking time $(5,10,15,20$ and $25 \mathrm{~min})$. After cooking, the cooked noodles were removed and drained for $30 \mathrm{~s}$, then quenched for $30 \mathrm{~s}$ in $8{ }^{\circ} \mathrm{C}$ water $(1: 10, \mathrm{w} / \mathrm{w})$. The quenched cooked noodles were drained for $30 \mathrm{~s}$, and the length, width and thickness of boiled WSN were measured immediately by using a vernier caliper. The swelling ratio of cooked WSN in the length, width or thickness was calculated by dividing the length, width or thickness of cooked WSN by the length, width or thickness of raw WSN, respectively. The moisture content of cooked WSN was determined by an air-oven method AACC 44-15A (AACC, 1995). After cooking, the WSN were stored in a plastic box for periods ranging from 0.5 to $7.5 \mathrm{~h}$ at $18 \pm 2{ }^{\circ} \mathrm{C}$ and at ambient relative humidity until the measurements of MRI, firmness and SEM being performed.

The effects of cooking time on the moisture content and swelling ratio of cooked WSN were assessed by analysis of variance (ANOVA) using the general linear model of SAS (version 6.11, SAS Institute, Cary, NC), 
then significant means were compared by the Duncan test at a level of $p<0.01$.

\section{3. $M R I$}

For the MRI investigation, a special sample holder was designed to fit the MRI gradient coil and shown in Fig. 1. The noodle stripes were fixed on the multi-layers of PVP plate in the sample holder, which was a cylinder $(6 \mathrm{~cm}$ inner diameter, $7 \mathrm{~cm}$ in length) made of acrylic plate. The multiple layers of PVP plates, which can be easily slid in and out, was allowed to investigate many stripes of noodles at the same time.

MRI was performed on a Bruker BioSpec 3T system (Ettlingen, Germany) equipped with a S116 mini-gradient coil ( $7 \mathrm{~cm}$ in inner diameter). All the images were acquired in the plane perpendicular to the longitudinal side of noodles using a two-dimensional (2D) Fourier transform technique. A standard spin-echo (SE) sequence was used to produce $T_{2}$-weighted images $(\mathrm{TE}=15 \mathrm{~ms}, \mathrm{TR}=3000 \mathrm{~ms})$. The multi-echo $(\mathrm{CPMG})$ sequence was used to calculate the proton transverse relaxation time $\left(T_{2}\right)$ maps. The multi-echo sequence parameters were repetition time $(\mathrm{TR})=3000 \mathrm{~ms}$, eight echo times $(\mathrm{TE})=15,30,45,60,75,90,105,120 \mathrm{~ms}$, pixel matrix $=256 \times 256$, field of view $(\mathrm{FOV})=60 \times 60 \mathrm{~mm}$, and slice thickness $=5 \mathrm{~mm}$. The spatial resolution was $234 \mu \mathrm{m}$. The measurement time was $12.8 \mathrm{~min}$ for one acquisition. For each sequence the gain and FT scale parameter were kept constant. The $T_{2}$ was calculated according to the Marquardt algorithm using a monoexponential fitting model. All the MRI measurement were performed at $18 \pm 2{ }^{\circ} \mathrm{C}$ in duplicates.

The heterogeneity of $T_{2}$ maps was expressed as the profiles of $T_{2}$ values on the central cross-section of cooked WSN that was carried out using homemade programs and $\operatorname{Excel}^{\odot}$. The $T_{2}$ map analysis was achieved from the $T_{2}$ histogram representing the $T_{2}$ value from 0 to $160 \mathrm{~ms}$ and the amount of pixel at a specific $T_{2}$ values. The histogram frequency was normalized by the total pixel numbers to prevent from any distortion of the histogram due to the different size of noodle MRI images.
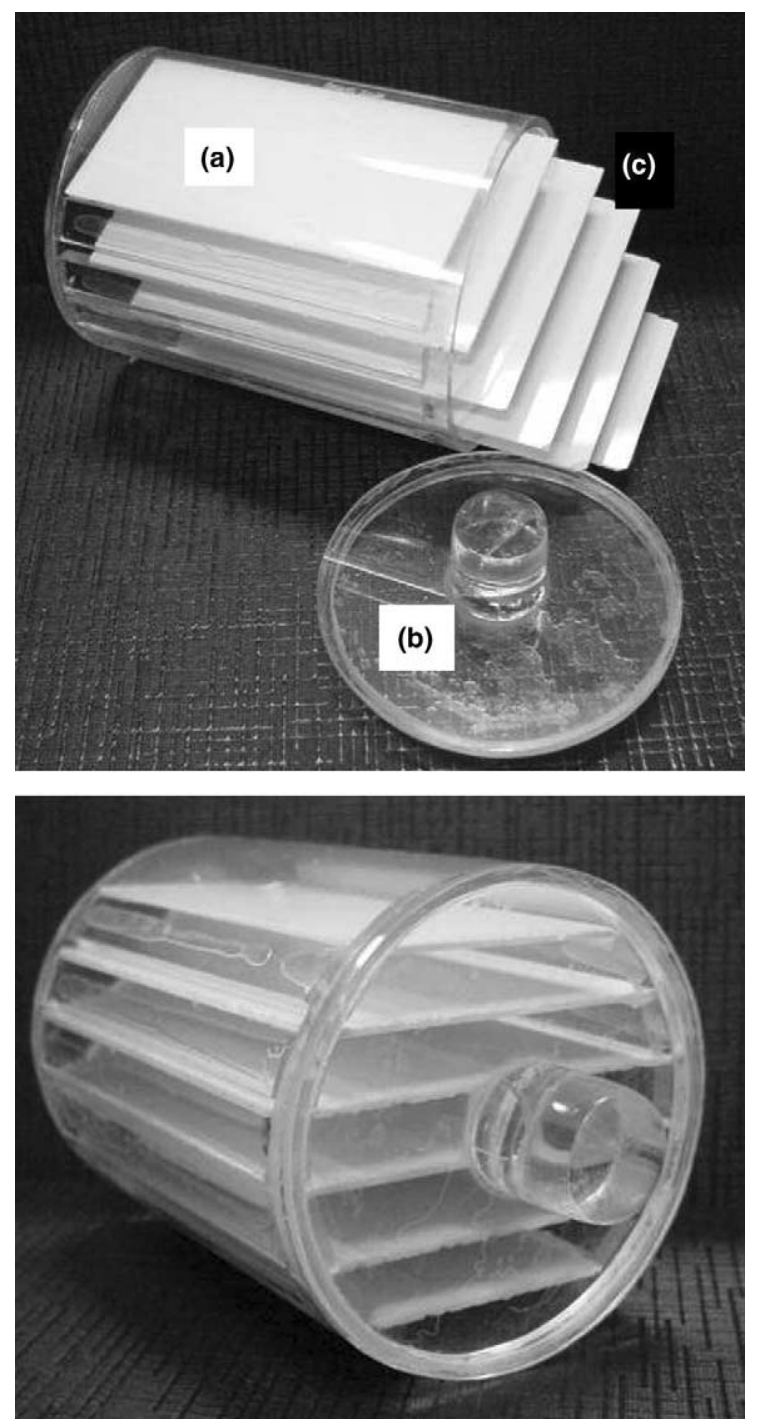

Fig. 1. Sample holder for MRI: (a) acrylic cylinder $(6 \mathrm{~cm}$ inner diameter, $7 \mathrm{~cm}$ in length); (b) lid; (c) multiple layers of PVP plates.

\subsection{Texture analysis}

Surface firmness and cutting firmness of cooked WSN were measured by using a texture analyzer (TA-XT2i, Stable Micro Systems, Surrey, UK) with the probes,

Table 1

The moisture content and swelling ratio of cooked white salted noodles with different cooking time

\begin{tabular}{|c|c|c|c|c|}
\hline \multirow[t]{2}{*}{ Cooking time (min) } & \multirow[t]{2}{*}{ Moisture content $(\%)$} & \multicolumn{3}{|c|}{ Swelling ratio $^{\mathrm{a}}$} \\
\hline & & Length & Width & Height \\
\hline 0 & $34.1 \pm 0.3^{\mathrm{a}}$ & - & - & - \\
\hline 5 & $55.7 \pm 0.2^{\mathrm{b}}$ & $1.20 \pm 0.01^{\mathrm{a}}$ & $1.26 \pm 0.01^{\mathrm{a}}$ & $1.02 \pm 0.03^{\mathrm{a}}$ \\
\hline 10 & $60.1 \pm 0.3^{\mathrm{c}}$ & $1.22 \pm 0.06^{\mathrm{a}}$ & $1.32 \pm 0.04^{\mathrm{ab}}$ & $1.00 \pm 0.05^{\mathrm{a}}$ \\
\hline 15 & $63.4 \pm 0.2^{\mathrm{d}}$ & $1.25 \pm 0.01^{\mathrm{a}}$ & $1.34 \pm 0.04^{\mathrm{bc}}$ & $1.11 \pm 0.06^{\mathrm{b}}$ \\
\hline 20 & $66.1 \pm 0.1^{\mathrm{e}}$ & $1.26 \pm 0.04^{\mathrm{a}}$ & $1.41 \pm 0.03^{\mathrm{c}}$ & $1.12 \pm 0.06^{\mathrm{b}}$ \\
\hline 25 & $68.8 \pm 0.3^{\mathrm{f}}$ & $1.33 \pm 0.04^{\mathrm{b}}$ & $1.49 \pm 0.05^{\mathrm{d}}$ & $1.34 \pm 0.04^{\mathrm{c}}$ \\
\hline
\end{tabular}

${ }^{a}$ The swelling ratio was calculated by dividing the length, width or thickness of cooked WSN by the length, width or thickness of raw WSN, respectively. The mean values in the same column with the different letters are significantly different $(p<0.01)$. 


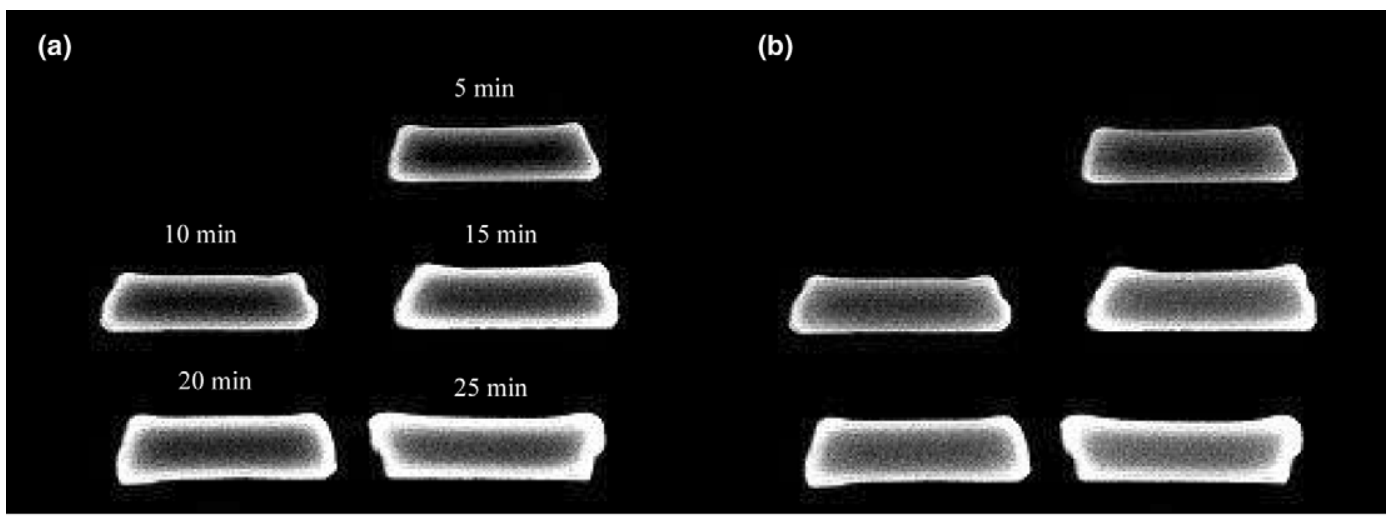

(c)

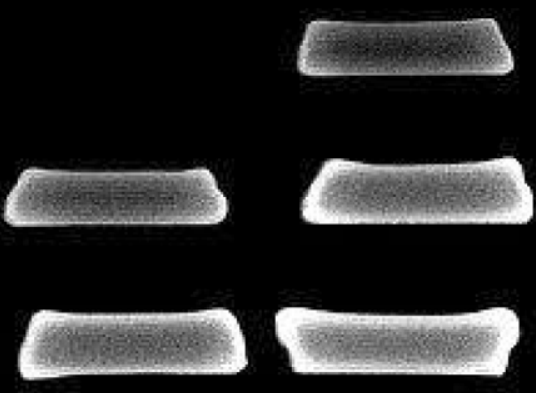

(d)
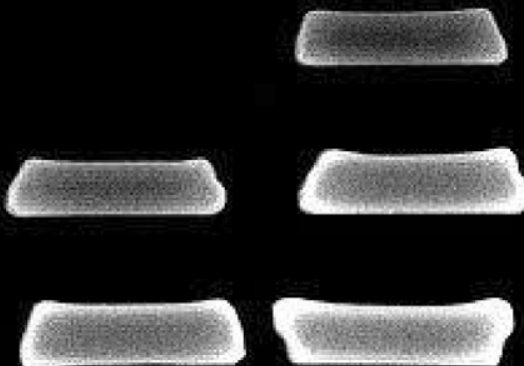

Fig. 2. $T_{2}$-weighted images of cooked WSN with different cooking time $(5,10,15,20$, and $25 \mathrm{~min}$ ) and storage time, (a) $0.5 \mathrm{~h}$, (b) $1.5 \mathrm{~h}$, (c) $2.5 \mathrm{~h}$, and (d) $7.5 \mathrm{~h}$.

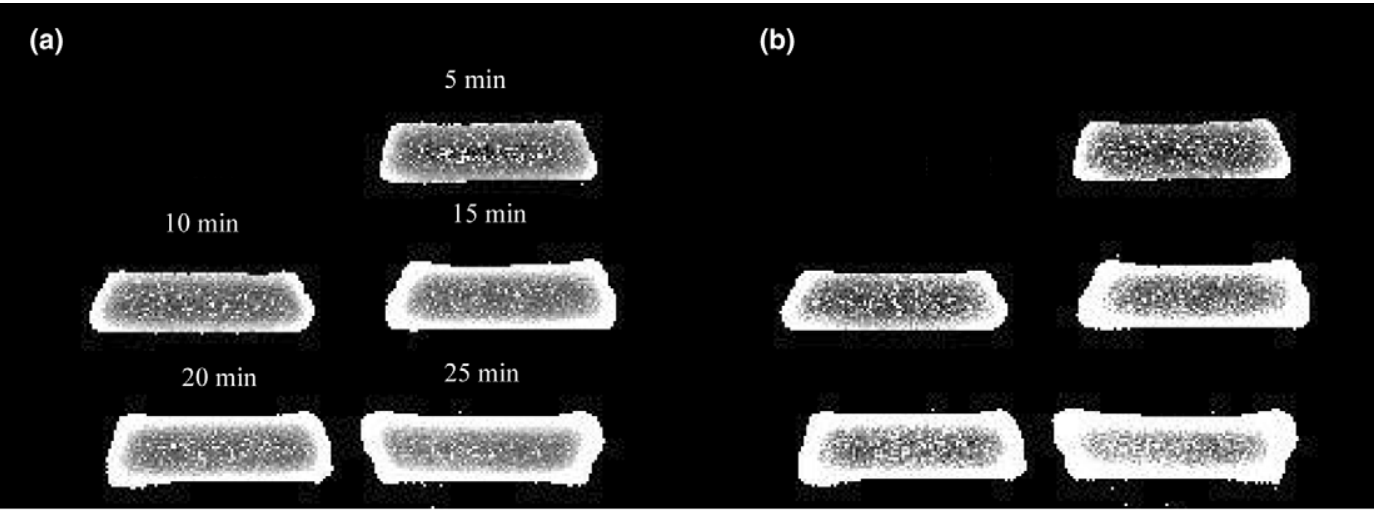

(c)

(d)
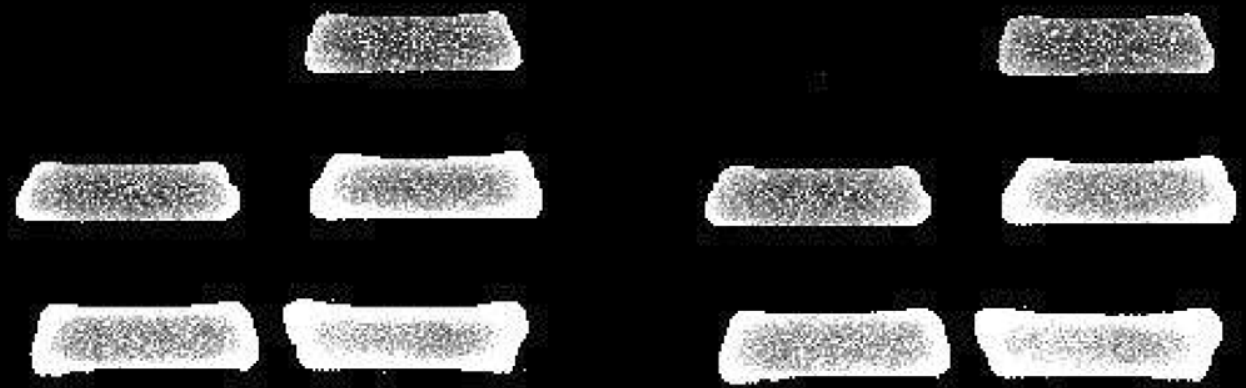

Fig. 3. $T_{2}$ maps of cooked WSN with different cooking time $(5,10,15,20$, and $25 \mathrm{~min}$ ) and storage time, (a) $0.5 \mathrm{~h}$, (b) $1.5 \mathrm{~h}$, (c) $2.5 \mathrm{~h}$, and (d) $7.5 \mathrm{~h}$. 
the pasta firmness/stickiness rig (HDP/PFS) and the light knife blade (A/LKB-F), respectively. Peak force was recorded as firmness $(\mathrm{g})$. The probe was attached to a $5 \mathrm{~kg}$ load cell. The measurements and data processing were run by the texture expert for Windows version 1 software (Stable Micro Systems, Surrey, UK). Both measurements were determined by performing the compression test mode with forwarding speed and withdrawal speed of $10 \mathrm{~mm} \mathrm{~s}^{-1}$ for probes. The surface firmness measurements were performed by compressing $1.9 \mathrm{~mm}$ in depth from the surface of two noodle strands with the compressing speed of $0.5 \mathrm{~mm} \mathrm{~s}^{-1}$. The cutting firmness measurements were performed by cutting two strands of cooked WSN with the cutting speed of $0.2 \mathrm{~mm} \mathrm{~s}^{-1}$. Seven replicates were measured and the higher and the lower
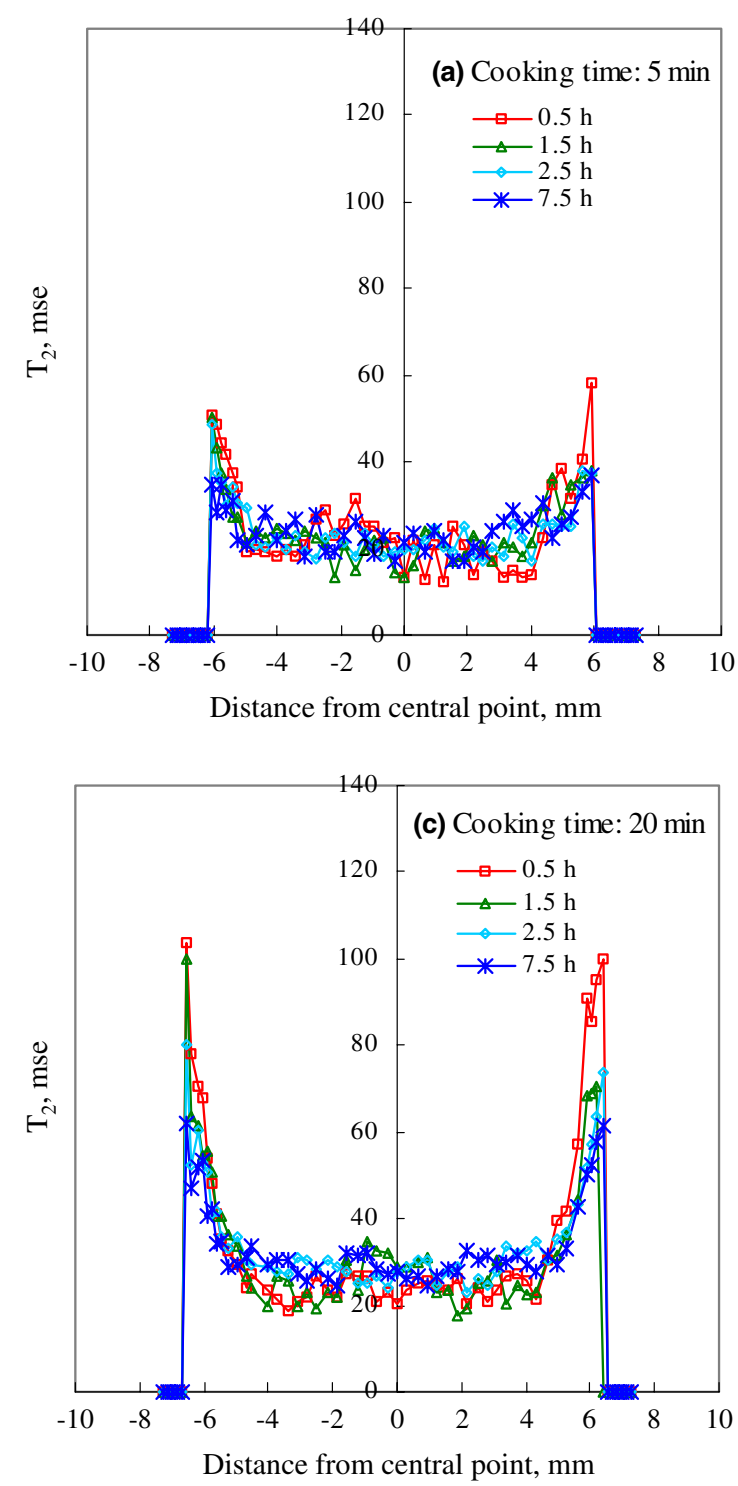

values were discarded, so that data were the means for five measurements with their standard deviations.

\subsection{Scanning electron microscopy}

Microstructure of the cross-section of noodles was investigated using SEM (JSM-6300, Jeol Co., Japan) at $10 \mathrm{kV}$ accelerating voltage. A $5 \mathrm{~mm}$ length noodle was rapidly frozen in liquid $\mathrm{N}_{2}$ for $30 \mathrm{~s}$, followed by freeze-drying for 3 days (Moss, 1974). The dried noodle was fractured by folding and mounted on a stainless steel specimen stub with the cross-section face up. The mounted sample were then dried at $40{ }^{\circ} \mathrm{C}$ for $3 \mathrm{~h}$ before $\mathrm{Au} / \mathrm{Pd}$ coating for $3 \mathrm{~min}$ at $10 \mathrm{~mA}$ by using an ion sputter (ion Sputtering Device JFC-1100E, Jeol Co., Japan).
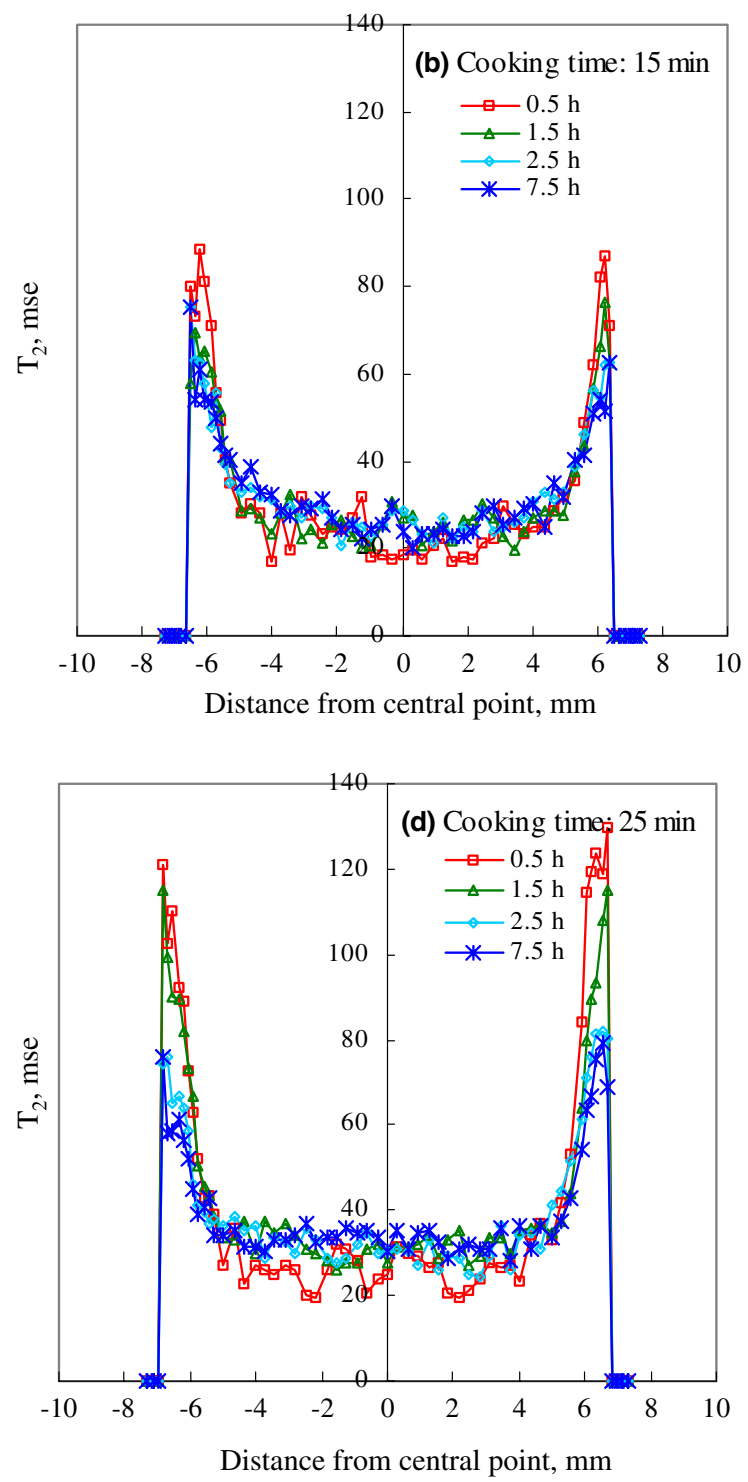

Fig. 4. Profiles of $T_{2}$ values along the central line on cross-section of cooked WSN with different cooking and storage time. 


\section{Results and discussion}

\subsection{Water absorption and swelling of WSN during cooking}

Table 1 shows the moisture content and swelling ratio of boiled WSN, which were cooked for 5, 10, 15, 20 and $25 \mathrm{~min}$. The water absorption of WSN during cooking increased significantly with the increases of cooking time. When WSN was cooked for $20 \mathrm{~min}$ the central white core of the noodles disappeared by visual observation and the moisture content was $66.12 \%$. Kojima et al. (2001) reported the similar results of the moisture contents of $3 \mathrm{~mm}$ square Japanese noodles which contained $60.9 \%, 67.3 \%$ and $69.0 \%$ when cooked in tap water for 8 , 16 and $24 \mathrm{~min}$, respectively. The swelling ratios of WSN also significantly increased with the increases of cooking time with the tendency of width $>$ length $>$ height. The high width swelling of WSN compared to the swelling of length and height of cooked WSN is mainly due to the geometric factors of WSN, i.e., short distance of water penetration across the width of WSN and large surface area of cross-section of WSN.

\subsection{MRI images of WSN under different cooking and storage time}

The degree of gelatinization and rate of retrogradation of starch in food systems were significantly affected by the amount of water absorption during cooking and water status during storage, which resulted in modifying the starch gel network structure of WSN and changing the texture and eating quality of boiled WSN (Crosbie, 1991; Liang, 1999; Seib, 2000). Figs. 2 and 3 are the $T_{2}$-weighted images and $T_{2}$ maps of cross-section of WSN during storage. The degree of swelling of WSN under various cooking times could be obviously observed on the images. Because the MRI signal intensity
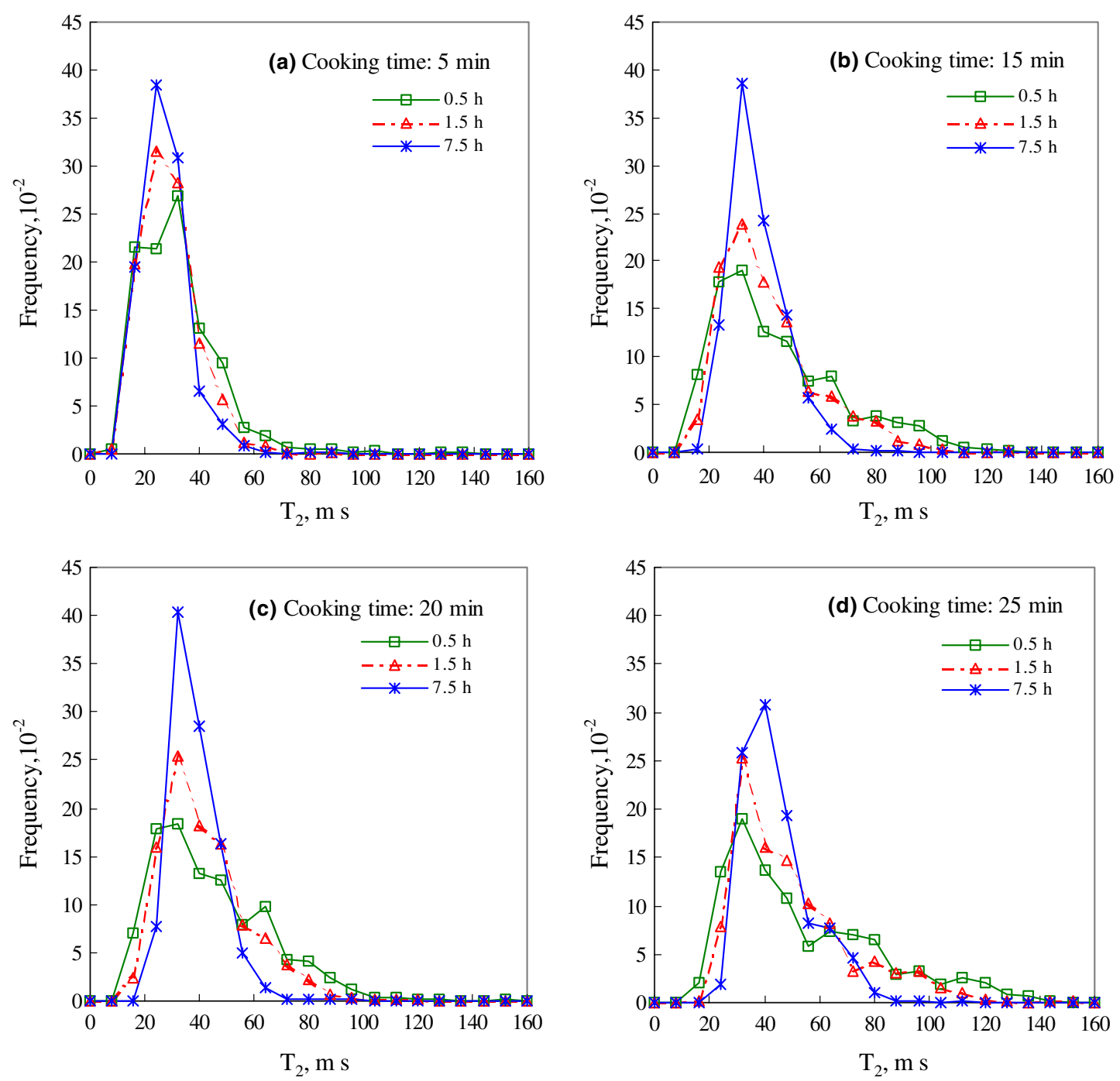

Fig. 5. $T_{2}$ histograms of cooked WSN with different cooking time and storage time. 
is not a simple effect, the signal intensity was depended on both water concentration and the degree of starch gelatinization of the cooked noodles. Non-homogeneous water status was clearly investigated in all noodles and was attributed to the differences in amount of water absorption during cooking, migration rate of water molecules during storage, and degree of protein denaturation, starch gelatinization and retrogradation. General speaking, two distinguished regions, a bright surface area in which highly hydrated and gelatinized WSN and a dark central area in which limited hydrated and gelatinized WSN were observed for all noodles stored up to $7.5 \mathrm{~h}$ (Fig. 2). The $T_{2}$ maps (Fig. 3) also showed that the area of brightness increased with the increase of cooking time and storage time. The decreases of brightness in surface region and the increases of brightness spots in central region revealed the results of water migration from the highly hydrated surface region to the limited hydrated central region. Therefore, both water concentration and water mobility changed as functions of spatial location and time.

In order to investigate the phenomena of water migration and quantify the water mobility of WSN during storage, the $T_{2}$ profiles of central cross-section of WSN was shown in Fig. 4. These profiles showed that there were large differences in $T_{2}$ values between surface region and core region of noodles. The differences of $T_{2}$ values at surface area and central area increased with the increase of cooking time but decreased with the increase of storage time. Initially, the $T_{2}$ values of surface region of WSN were about $60,90,100$ and $120 \mathrm{~ms}$ for the noodles cooked for 5, 15, 20 and $25 \mathrm{~min}$, and the $T_{2}$ values of central region were about $15-35 \mathrm{~ms}$ in all noodles when they were stored for $0.5 \mathrm{~h}$. After $2.5 \mathrm{~h}$ of storage, the $T_{2}$ values of surface area were about $60-80 \mathrm{~ms}$ and $T_{2}$ values of central area were about 20 $40 \mathrm{~ms}$, except for the WSN cooked for $5 \mathrm{~min}$. After storage for $7.5 \mathrm{~h}$, the surface $T_{2}$ values were about $40,60,70$ and $80 \mathrm{~ms}$ for WSN cooked for 5, 15, 20 and $25 \mathrm{~min}$. Although $T_{2}$ values at the central regions of WSN were not significantly different during storage, fewer variations of $T_{2}$ value were observed for the WSN cooked for $25 \mathrm{~min}$ (Fig. 4(d)) than WSN cooking for 5 min (Fig. 4(a)) when they were stored for $1.5 \mathrm{~h}$. The water migration from surface region to central region were significant observed in 20 and $25 \mathrm{~min}$ cooked WSN but not in 5 and 10 min cooked WSN because higher total water absorption when WSN was cooked for longer time. Limited water restricted the gelatinization of starch of noodle and resulted in uneven degrees of starch gelatinization and protein denaturation of noodles. These could be further proved by SEM micrographs, in which the starch granules maintained intact (Fig. 7(a) and (b)).

Fig. 5 showed the distribution of $T_{2}$ values of crosssection of WSN. In general, the $T_{2}$ value distribution varied from a broader multi-peak to a narrow single- peak for the cooked WSN when stored for $7.5 \mathrm{~h}$ with the exception of the 25 min cooked WSN. The major $T_{2}$ value of $5 \mathrm{~min}$ cooked WSN was $32 \mathrm{~ms}(27 \%)$ after storage for $0.5 \mathrm{~h}$ and it was shifted to $24 \mathrm{~ms}(38 \%)$ after storage for $7.5 \mathrm{~h}$. The major $T_{2}$ values of WSN cooked for 15 and $20 \mathrm{~min}$ were the same $(32 \mathrm{~ms})$ and not changed during storage. The frequency of major $T_{2}$ value increased from $18 \%$ to $40 \%$ when stored for $7.5 \mathrm{~h}$ for both noodles. But, the ranges of $T_{2}$ distribution were different between $15 \mathrm{~min}$ cooked WSN (8-144 ms) and $20 \mathrm{~min}$ cooked WSN (16-152 ms) when stored for $0.5 \mathrm{~h}$. After stored for $7.5 \mathrm{~h}$, the ranges of $T_{2}$ distribution of both noodles decreased, i.e., $16-96$ and $16-116 \mathrm{~ms}$ for 15 and $20 \mathrm{~min}$ cooked WSN. The major $T_{2}$ value of 25 min cooked WSN shifted from $32(19 \%)$ to $40 \mathrm{~ms}$ $(31 \%)$ and the ranges of distribution were decreased from $16-152$ to $24-128 \mathrm{~ms}$ after storage of $7.5 \mathrm{~h}$.

Traditionally, the optimal cooking time of raw or dried noodles is empirically decided by the observation when the uncooked central core of noodles has just disappeared (Shibata, 1984). That is, the optimal cooking time of WSN prepared in this study was ca. $20 \mathrm{~min}$ judged by vision. The MRI results shown in Fig. 5 indicated that the major $T_{2}$ values of noodles cooking for 15-25 min were around $32 \mathrm{~ms}$ but the distribution of $T_{2}$ values was getting narrower when the storage time was getting longer. Although the distributions of $T_{2}$ values were not easy to distinguish the WSN having been under, optimal or over cooked, the distributions of $T_{2}$
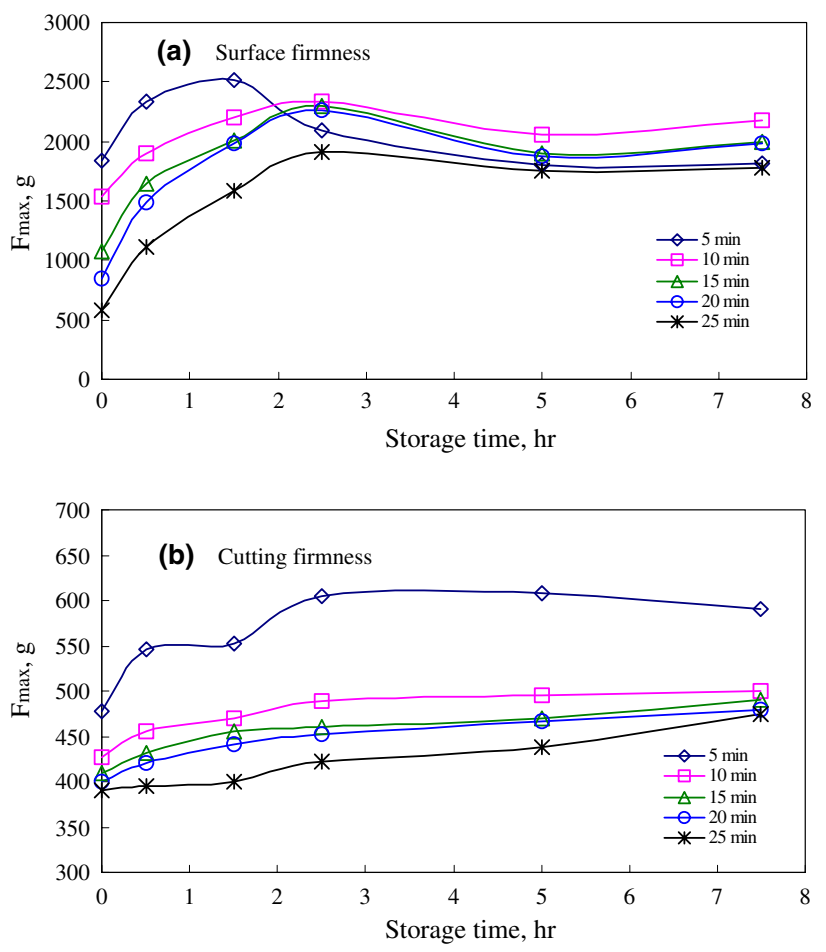

Fig. 6. (a) Surface firmness and (b) cutting firmness of cooked WSN with different cooking and storage time. 
values revealed the characters of water status of boiled WSN during storage. It was interested to notice that the water migration and redistribution was observed all the time in all noodles, and no consistent moisture contents or the same water mobility in noodles was observed even stored up to $7.5 \mathrm{~h}$.

\subsection{Texture and SEM of cooked WSN with different cooking and storage time}

Fig. 6 showed the surface firmness and cutting firmness of WSN cooked for 5, 10, 15, 20 and $25 \mathrm{~min}$ and stored up to $7.5 \mathrm{~h}$ at $18 \pm 2{ }^{\circ} \mathrm{C}$. The surface firmness of noodles decreased with increases of boiling time but increased with increasing in storage time up to 2 or
$3 \mathrm{~h}$ for WSN cooked for 5 min or longer (Fig. 6(a)). The 5 min cooked WSN showing the largest surface firmness right after cooking than others was attributed to the short cooking time that resulted in low water absorption and limited hydration. Since the surface firmness measured the force required to compress the $1.9 \mathrm{~mm}$ depth from the surface of WSN, the transitions of surface firmness of cooked WSN from increasing to decreasing during storage periods was partially due to the loss of surface water. The transition times of surface firmness of cooked WSN during storage agreed with the findings in the MRI $T_{2}$ profiles (Fig. 4(b)-(d)), in which the differences of $T_{2}$ values between surface and central regions of 15,20 and 25 min cooked WSN were significantly decreased. The cutting firmness of all noodles decreased
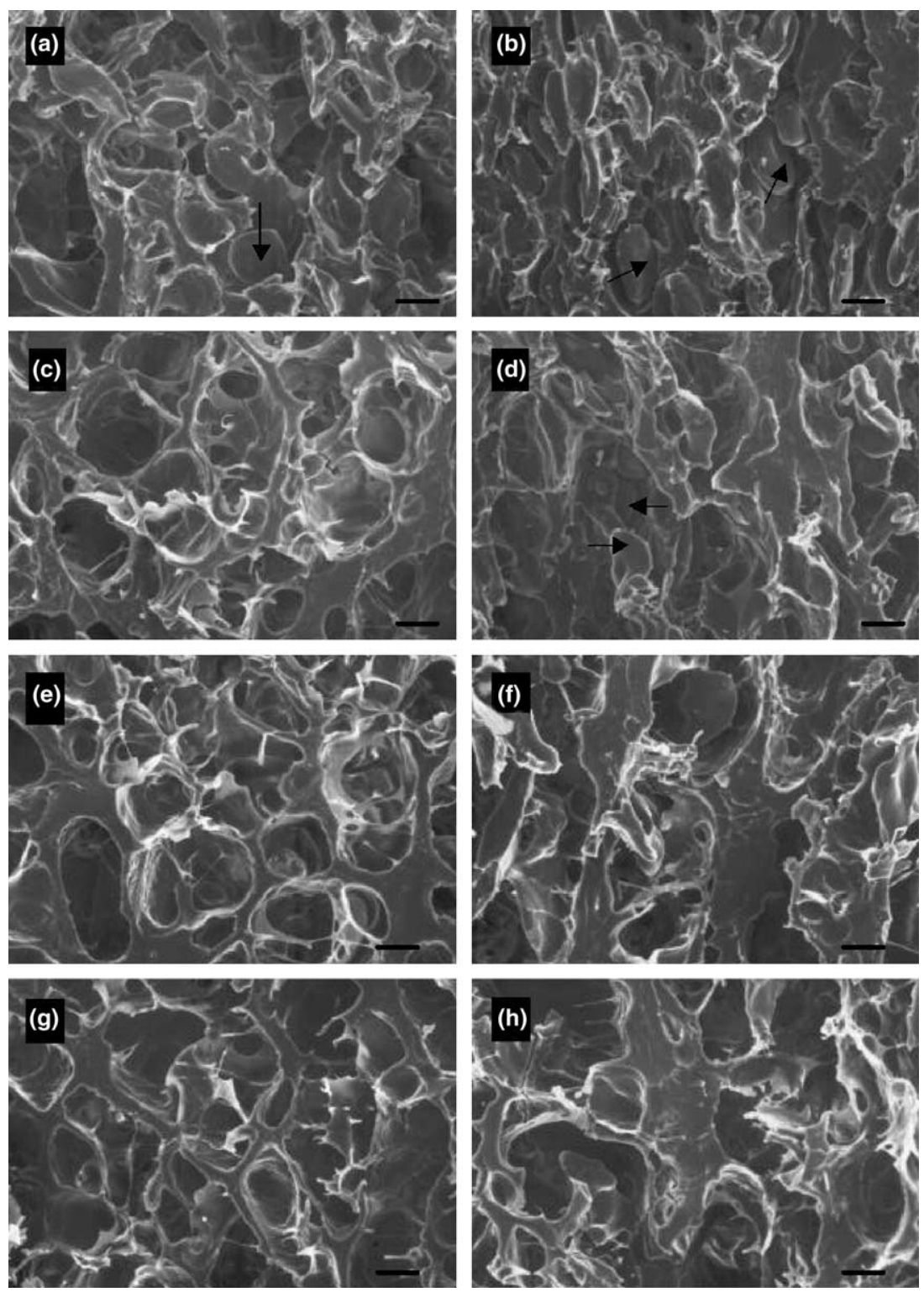

Fig. 7. SEM micrographs of fresh cooked WSN with different cooking time: (a) 5 min, surface; (b) 5 min, center; (c) 15 min, surface; (d) 15 min, center; (e) $20 \mathrm{~min}$, surface; (f) $20 \mathrm{~min}$, center; (g) $25 \mathrm{~min}$, surface; (h) $25 \mathrm{~min}$, center (bar $(-)=10 \mu \mathrm{m}$; arrow $(\rightarrow)=$ starch granule). 
with the increases of cooking time during the whole storage period (Fig. 6(b)). During the storage, the increases of cutting firmness with increases of storage time of WSN were attributed to the retrogradation of starch gel (Liang, 1999; Seib, 2000).

As observed by SEM micrographs (Fig. 7), the starch granules at highly hydrated surface region considerably swelled and did not retain their original granular form, while some of intact starch granules could be also observed in the limited hydrated central regions. Because there was not enough water taken by 5 min cooked WSN, many starch granules remaining intact in both surface and core regions (Fig. 7(a) and (b)). Even cooked for $15 \mathrm{~min}$ the some starch granules could also be observed in central region (Fig. 7(d)). The longer cooking time caused higher water absorptions that provide much more water for starch gelatinization and protein denaturation. The higher degrees of starch gelatinization and protein denaturation were observed in both surface and central region of 20 and $25 \mathrm{~min}$ cooked WSN (Fig. 7(e)-(h)).

It has been reported that the characteristic texture of boiled noodles was greatly affected by the moisture distribution and the homogenization of moisture content inside noodles after holding was responsible for the loss of elasticity and viscosity of noodles (Kojima et al., 2001; Liang, 1999; Seib, 2000). Although only the surface and cutting firmness of boiled WSN was observed in this study, the characterization of water mobility of cooked WSN during storage was well responsible for the changes of hardness of noodles. The optimal cooking time ensures that the optimal moisture content for starch gelatinization which can be monitored by the distribution of $T_{2}$ values. Besides, the profile of $T_{2}$ values during storage is helpful in investigating the water migration that corresponded well with the changes of hardness of noodles during storage.

\section{Conclusion}

The MRI is a powerful technique to investigate the water characteristics of cooked WSN during storage non-invasively and non-destructively. The results shown in this study provide important information for the relationship between the water status, resulting from water distribution and migration during the cooking and storage, and the changes of noodles' texture. The hardness of cooked WSN during storage was well corresponded with the water migration observed by the changes of $T_{2}$ profiles and distribution. Besides, the sample holder designed for MRI observation, holding up to several strands of noodles for analysis would be effective for rapid multi sample analysis, enabling statistical analysis of samples and/or treatment. More studies should be also conducted to correlate the water characterization to the eating quality of noodles such as elasticity, stickiness and extensibility.

\section{Acknowledgment}

This work was supported by the Grant NSC 89-2313B-002-182 from the National Science Council, Taipei, Taiwan.

\section{References}

AACC. (1995) Methods 08-01, 38-10, 44-15A, 46-12. In Approved method of the American Association of Cereal Chemists (9th ed.). $\mathrm{MN}$ : AACC Inc.

Baik, B. K., Czuchajowska, Z., \& Pomeranz, Y. (1994). Role and contribution of starch and protein contents and quality to texture profile analysis of oriental noodles. Cereal Chemistry, 71, 315-320.

Crosbie, G. B. (1991). The relationship between starch swelling properties, paste viscosity and boiled noodle quality in wheat flours. Journal of Cereal Science, 13, 145-150.

Fukuoka, M., Mihori, T., \& Watanabe, H. (2000). MRI observation and mathematical model simulation of water migration in wheat flour dough during boiling. Journal of Food Science, 65, 1343-1348.

Guan, F., \& Seib, P. A. (1994). Instrumental probe and method to measure stickiness of cooked spaghetti and noodles. Cereal Chemistry, 71, 330-337.

Janto, M., Pipatsattayanuwong, S., Kruk, M. W., Hou, G., \& McDaniel, M. R. (1998). Developing noodles from US wheat varieties for the far east market: Sensory perspective. Food Quality and Preference, 9, 403-412.

Kim, W. S., \& Seib, P. A. (1993). Apparent restriction of starch swelling in cooked noodles by lipids in some commercial wheat flours. Cereal Chemistry, 70, 367-372.

Kojima, T. I., Horigane, A. K., Yoshida, M., Nagata, T., \& Nagasawa, A. (2001). Change in the status of water in Japanese noodles during and after boiling observed by NMR micro imaging. Journal of Food Science, 66, 1361-1365.

Konik, C. M., Miskelly, D. M., \& Gras, P. W. (1992). Contribution of starch and non-starch parameters to the eating quality of Japanese white salted noodles. Journal of the Science of Food and Agriculture, 58, 403-406.

Konik, K. M., Miskelly, D. M., \& Gras, P. W. (1993). Starch swelling power, grain hardness and protein: Relationship to sensory properties of Japanese noodles. Starch, 45, 139-144.

Lai, H. M., Schmidt, S. J., Chiou, R. G., Slowinski, L. A., \& Day, G. A. (1993). Mobility of water in a starch-based fat replacer as studied by ${ }^{17} \mathrm{O}$ NMR spectroscopy. Journal of Food Science, 58, $1103-1106$

Liang, X. (1999). Gel properties of noodle flours and their wheat starches measured by dynamic-rheometry: Matching storage moduli of low-swelling flour to high-swelling flours by adding modified starches. Ph.D. Dissertation, Kansas State University, Manhattan.

Moss, R. (1974). Dough microstructure as affected by the addition of cysteine, potassium bromate, and ascorbic acid. Cereal Science Today, $19,557-561$

Moss, R., Gore, P. J., \& Murray, I. C. (1987). The influence of ingredients and processing variables on the quality and microstructure of Hokkien, Cantonese and instant noodles. Food Microstructure, 6, 63-74.

Nagao, S., Ishibashi, S., Imai, S., Sato, T., Kanbe, Y., Kaneko, Y., et al. (1977). Quality characteristics of soft wheats and their utilization in Japan. II. Evaluation of wheats from the United States, Australia, France and Japan. Cereal Chemistry, 54, 198-204. 
Oda, M., Yasuda, Y., Okazaki, S., Yamauchi, Y., \& Yokoyama, Y. (1980). A method of flour quality assessment for Japanese noodles. Cereal Chemistry, 57, 253-254.

Oh, N. H., Seib, P. A., Deyoe, C. W., \& Ward, A. B. (1983). Noodles. I. Measuring the textural characteristics of cooked noodles. Cereal Chemistry, 60, 433-438.

Ruan, R. R., \& Chen, P. L. (1998). Aspects of water in food and biological systems. In Water in foods and biological materials: A nuclear magnetic resonance approach (pp. 51-73). MN: Technomic publishing Co.

Schmidt, S. J., \& Lai, H. M. (1991). Use of NMR and MRI to study water relations in foods. In H. Levine, \& L. Slade (Eds.), Water relationships in foods-advances in the 1980s and trends in the 1990s (pp. 405-452). New York: Plenum press.

Schmidt, S. J., Sun, X., \& Litchfield, J. B. (1996). Applications of magnetic resonance imaging in food science. Critical Review of Food Science and Nutrition, 36, 357-385.

Seib, P. A. (2000). Reduced-amylose wheats and Asian noodles. Cereal Foods World, 45, 504-512.

Shibata, S. (1984). The science of the taste of udon (Japanese noodles). Shokuhin to Kagaku, 7, 80-84.

Slade, L., \& Levine, H. (1991). A food polymer science approach to structure-property relationships in aqueous food systems: Non- equilibrium behavior of carbohydrate-water systems. In H. Levine, $\&$ L. Slade (Eds.), Water relationships in foods-advances in the 1980 s and trends in the 1990s (pp. 29-101). New York: Plenum press.

Stapley, A. G. F., Hyde, T. M., Gladden, L. F., \& Fryer, P. J. (1997). NMR imaging of the wheat grain cooking process. International Journal of Food Science and Technology, 32, 355-375.

Takano, H., Ishida, N., Koizumi, M., \& Kano, H. (2002). Imaging of the fermentation process of bread dough and the grain structure of baked breads by magnetic resonance imaging. Journal of Food Science, 67, 244-250.

Takeuchi, S., Fukuoka, M., Gomi, Y. I., Maeda, M., \& Watanabe, H. (1997). The change of moisture distribution in a rice grain during boiling as observed by NMR imaging. Journal of Food Engineering, 33, 281-297.

Wang, L., \& Seib, P. (1996). Australian salt-noodle flours and their starches compared to US wheat flours and their starches. Cereal Chemistry, 73, 167-175.

Webb, G. A., Belton, P. S., Gil, A. M., \& Delgadillo, I. (2001). Magnetic resonance in food science: A view to the future. Cambridge: The Royal Society of Chemistry.

Yun, S. H., Rema, G., \& Quail, K. (1997). Instrumental assessments of Japanese white salted noodle quality. Journal of the Science of Food and Agriculture, 74, 81-88. 